**This manuscript has been accepted for publication in the Journal of Experimental Child

$$
\text { Psychology** }
$$

Preschool children weigh accuracy against partisanship when seeking information Lisa Chalik ${ }^{1 *}$, Harriet Over $^{2}$, and Yarrow Dunham ${ }^{3}$

\author{
${ }^{1}$ Yeshiva University \\ ${ }^{2}$ University of York \\ ${ }^{3}$ Yale University
}

*Correspondence should be addressed to Lisa Chalik, Yeshiva University, Stern College for Women, 215 Lexington Ave., rm. 404, New York, NY 10016, lisa.chalik@yu.edu

Acknowledgments: We are very grateful to Sarah Finkelstein, Katharine Morris, Leetal Winick, Shira Levy, Nina Miller, Devora Tuchman, Yael Feder, Elisheva Zahtz, Rachel Baitch, and Estee Lichtenstein for their assistance with data collection. We are also grateful to the staff and families at the Liberty Science Center, the Connecticut Science Center, and the Yale Peabody Museum of Natural History for participating in this research, and to the families and staff at all of the participating schools in Connecticut and New York. Funding was provided by a grant from the Templeton Foundation (56036) to YD. Additional funding was provided by the European Research Council under the European Union's Horizon 2020 programme, grant number ERC-STG-75571 to HO, and a Momentum Scholar's Award from the Center for the Science of Moral Understanding to LC. 


\begin{abstract}
The present work asks how preschool-aged children $(N=200)$ weigh accuracy against partisanship when seeking information. When choosing between a story that favored the ingroup, but came from an unreliable source, versus a story that favored the outgroup, but came from a reliable source, children were split between the two; although they tracked both reliability and bias, they were conflicted about which to prioritize. Furthermore, children changed their opinions of the groups after hearing the story they had chosen: Children who heard an unreliable, ingroup-favoring story ended up more biased against the outgroup, even while recognizing that the story's author was not a trustworthy source of information. Implications for the study of susceptibility to misinformation are discussed.
\end{abstract}

Keywords: Intergroup cognition, social cognitive development, information seeking, minimal groups, misinformation 


\section{Preschool children weigh accuracy against partisanship when seeking information}

One of the fundamental challenges of childhood is figuring out where to turn for accurate information. Children are often referred to as "little scientists," interacting with their environment in ways that will allow them to uncover truths about how the world works (Chouinard et al., 2007; Gopnik \& Meltzoff, 1997; Gopnik \& Wellman, 2012; Wellman \& Gelman, 1992). Part of this process involves learning from the adults around them. However, relying on adults for information is not a straightforward task. No single adult holds all of the information that a child might want, and there are a variety of individual features that can make an adult more or less informative in a given situation.

Despite these challenges, young children are quite successful in seeking out reliable information about the world. One effective strategy that they use to accomplish this task is to listen to people who have been good sources of information in the past. Across a variety of experimental paradigms, children care about accuracy, preferring accurate to inaccurate informants (Clément et al., 2004; Harris et al., 2018; Harris \& Corriveau, 2011; Koenig et al., 2004; Koenig \& Harris, 2005; Pasquini et al., 2007). Most of this work has introduced children to two people, one with a history of accuracy and the other with a history of inaccuracy (e.g., when labeling objects), and asked them which person they'd like to seek further information from (e.g., about how to label or use a novel object). These studies have consistently shown that children attend to the past accuracy (or lack thereof) of informants, and use it to guide their future learning decisions. Children sometimes even prioritize concerns for accuracy over other features of informants. For example, 4- to 5-year-old children endorse information provided by an accurate informant with a non-native accent over information provided by an inaccurate informant with a native accent, despite generally placing more trust in people with native accents 
(Corriveau et al., 2013). Young children also prioritize accuracy over the age of informants (i.e., whether they are an adult or a child) when deciding whom to trust, even though they generally view adults as more informative than children (Jaswal \& Neely, 2006), and prioritize accuracy over the familiarity of informants, even though they usually prefer people who are familiar to them (Corriveau \& Harris, 2009). All of these findings suggest that children exert particular effort toward finding ways to efficiently learn accurate information about the world.

Yet, accuracy is not the only feature of informants that children attend to when seeking information. One factor that powerfully influences children's behaviors and decisions is their general tendency toward partisanship. Young children show biases in favor of their ingroups across a wide range of social distinctions, such as race, gender, religion, nationality, and even minimal groups (those that are arbitrary and meaningless; Baron \& Banaji, 2006; Dunham et al., 2006, 2011; Halim et al., 2017; Heiphetz et al., 2013; Kinzler et al., 2007). Importantly, because of these biases, children use group membership to guide their learning decisions (Elashi \& Mills, 2014; Hetherington et al., 2014; MacDonald et al., 2013; Zhang \& Sylva, 2021), preferring to learn information from ingroup members rather than from outgroup members. Furthermore, when attempting to learn information about social groups themselves, children seek out information that confirms their partisan biases: Preschoolers given a choice between a story by an author who favors their ingroup, and one by an author who favors their outgroup, choose to hear the ingroup-favoring information (Over et al., 2018).

Thus, accuracy and group bias are both important drivers of children's informationseeking tendencies. But, these two factors do not always align with one another. For example, consider the phenomenon of online misinformation among adults. When seeking information online, there is sometimes a tradeoff between pursuing headlines that come from reliable sources 
and pursuing headlines that appear to confirm partisan biases (i.e., misinformation). Despite the fact that most people report that they care about reading and sharing accurate news items (Pennycook et al., 2021), misinformation has been spread widely on social media platforms in recent years (Lazer et al., 2018). Some work even suggests that people share misinformation intentionally to promote group-based concerns (Brady et al., 2020; Osmundsen et al., 2021). Adults often decide, then, to overlook their concerns for accuracy in order to spread support for their partisan biases.

The present work tests how children navigate these types of tradeoffs - when the perceived accuracy and partisanship of a source of information conflict, which do children prioritize? There are certain types of information — specifically, group-specific norms and customs - that children anticipate ingroup members are more likely to know than outgroup members (Schmidt et al., 2012). Thus, there are certainly situations where children should pursue information that comes from within the ingroup, since that information is most likely to be accurate. Yet, for a great deal of information, it is unlikely that ingroup members will consistently be more or less accurate than outgroup members. Thus, when seeking information, both about the social groups in the immediate environment and about other aspects of the world, children must weigh their concerns for accuracy against their group-based biases to decide which sort of information to pursue.

Furthermore, once children have chosen the information that they would like to pursue, how do they learn from that information? Children's information-seeking choices have the potential to shape the ways in which they learn about the world (and specifically, about social groups) in a variety of ways. One possibility is that children internalize all of the information that they receive, revising their beliefs in ways that are fully consistent with whatever information 
has been presented to them. An alternate possibility, however, is that children do not learn from all types of information equally. Critically in the present context, both adults and children are subject to confirmation bias (Nickerson, 1998), by which they interpret information in ways that confirm their preexisting beliefs, and ignore information that disconfirms those beliefs. In the context of social groups, then, children may learn selectively from the information that they have pursued, revising their knowledge of and attitudes toward ingroups and outgroups in ways that confirm the biases that they already hold. As evidence for this possibility, children remember more positive information about ingroups than outgroups (Dunham et al., 2011) and interpret ambiguous scenarios in ways that present ingroup members more positively than outgroup members (Dunham \& Emory, 2014). An open question, however, is how children's learning biases may interact with their knowledge of the reliability of the information that they have received.

Here, we test how children work through the above challenges by asking two questions. First, when seeking information about social groups, do children prioritize the accuracy of the source or the partisan nature of the information? We give children a choice between two stories, one by an author who is reliable but favors the outgroup, and one by an author who is unreliable but favors the ingroup. Second, we ask how effective the sought out information is at influencing children's beliefs by testing whether children's biases change in response to the story they have chosen. We use a minimal groups paradigm to test children's attitudes involving groups that they have no prior knowledge of, and we focus on 4- to 6-year-old children in order to target the age at which children first begin to express explicit group-based biases (Dunham et al., 2011) and show concerns for accuracy (Koenig et al., 2004). Sampling criteria, hypotheses, and analyses (except where noted below) were preregistered on the Open Science Framework. Details of 
preregistrations, as well as raw data, code, and materials, can be found at https:// https://osf.io/8qv3s/.

\section{Study 1}

In Study 1, we expose children to three conditions: one where they can choose between reliable and unreliable stories, one where they can choose between ingroup-favoring and outgroup-favoring stories, and one where the reliability status and group bias of the stories conflict with one another. We hypothesize that in the absence of conflict between these two factors, children will choose to hear a reliable story over an unreliable one and an ingroupfavoring story over an outgroup-favoring one. When reliability status and group bias conflict, we do not have a directional prediction; if children are primarily interested in hearing reliable information, they will choose the reliable, outgroup-favoring story, and if children are primarily interested in hearing information biased in favor of their ingroup, they will choose the unreliable, ingroup-favoring story. We also test children's opinions of the two groups before and after hearing the story.

\section{Methods}

\section{Participants}

Participants were 72 4- to 6-year-old children $(M$ age $=5.45$, range $=4.13-6.97,40$ female, 32 male) recruited at preschools and museums in Connecticut. This sample size was established and preregistered prior to data collection, based on prior work. Participants were 53\% White, 1\% Black, 3\% Asian, 4\% Mixed race, and 39\% Unreported. For children recruited at schools, consent forms were sent home and returned by parents, and children were tested in quiet rooms at their schools. For children recruited at museums, families were approached by researchers and invited to participate in science experiments, and children were tested 
immediately in a quiet space. An additional 25 children were tested but excluded from analysis: 1 because of experimenter error, 1 because of parental interference, 1 because of developmental delays, 5 for failing to complete the entire activity, and 17 because they failed more than $25 \%$ of the attention check questions (explained below). For all three studies, all exclusion criteria were established and preregistered prior to data collection - these criteria resulted in an atypically high number of children being excluded from analysis. To ensure that these exclusions did not influence our patterns of findings, we re-ran all of our main analyses including all of the excluded participants; these analyses yielded patterns similar to those reported below. Across all three studies, there were no effects of age or gender $(p \mathrm{~s}>.53)$, so these factors are not discussed in our main analyses.

\section{Procedure}

The full script of the procedure is available on the Open Science Framework (https://osf.io/8qv3s/). The experimenter first assigned children to one of two minimal groups, labeled "the Green group" and "the Orange group," by instructing them to pick a coin out of a bag filled with a 50-50 mix of green and orange coins; each child received a sticker and wristband to remind them which group they were in. Children were then introduced to a 5-point smiley face scale, ranging from smiling to frowning, and were asked two questions to probe how much they liked each group; whether children were first asked about the ingroup or the outgroup was counterbalanced across participants. For the first question, the experimenter asked, "How much do you like or not like the [Green/Orange] group? Do you really like them [coded as 2], kind of like them [coded as 1], think they're okay [coded as 0], kind of not like them [coded as 1], or really not like them [coded as -2]?" For the second question, the experimenter asked, "How much do you want to play with the [Green/Orange] group? Do you really want to play 
with them [coded as 2], kind of want to play with them [coded as 1], think playing with them would be okay [coded as 0 ], kind of not want to play with them [coded as -1 ], or really not want to play with them [coded as -2]?"

Next, children were introduced to the story authors through videos (see Figure 1). The authors were two White, female, native-English-speaking university students, seated side by side. In the reliability video, which was intended to show children that one author was a reliable source of information and one was an unreliable source of information, the authors saw a series of objects placed between them, one at a time. For each object, the authors looked at the object, one at a time, and said, "I know what that is. That's a [label]." The reliable author labelled every object correctly, and the unreliable author labelled every object incorrectly. In the groups video, which was intended to show children that one author was biased in favor of the ingroup and one was biased in favor of the outgroup, the authors spoke, one at a time, saying, "I'm going to write a story about times people in the [Green/Orange] group did nice things, and people in the [Orange/Green] group did mean things." This language was intended to communicate to children that the stories were accounts of actual events that had occurred, and thus were true.

Which of the above two video(s) children saw varied by condition. In the focal condition, children saw both the reliability and groups video, in counterbalanced order. Children in the reliability condition saw only the reliability video (and thus received no information about the authors' group biases), and children in the groups condition saw only the groups video (and thus received no information about the authors' reliability status). After learning about the two authors, children answered a series of attention check questions. For these questions, children had to state whether each author had been accurate or inaccurate (in the reliability and focal conditions; "Can you remind me, did she say all those things before right or wrong?") and 
whether each author's story was biased in favor of the ingroup or the outgroup (in the groups and focal conditions; "Is her story about times people in your group or the other group do nice things?"). They also had to state which group they were in. In the focal condition, the unreliable actor was always biased in favor of the ingroup, and the reliable actor was always biased in favor of the outgroup. In each video, the author on the left always spoke first. The left-right position of the authors and which author was biased in favor of the ingroup (and thus was unreliable) were counterbalanced across participants.

After completing the attention check questions, children were asked to choose which story they wanted to hear, and the experimenter read the story that the child had chosen. Each story contained four pages, with each page depicting a different social interaction (all stories are available on the Open Science Framework, https:/osf.io/8qv3s/). Two of these interactions were positive (e.g., "One day, a kid from the Orange group shared a cookie with another kid.”) and two of these interactions were negative (e.g., "One day, a kid from the Green group hit another kid."). In the ingroup-favoring story, the positive actions were performed by a member of the child's ingroup and the negative actions were performed by a member of the child's outgroup; the outgroup-favoring story contained the reverse. The recipients of the behaviors were not described as belonging to either group (i.e., their group identity was ambiguous). The cover of each story was a playground scene with no characters present.

After hearing the story, children answered the same two liking questions that they had answered at the beginning of the study, and answered another series of attention check questions - these questions were the same as the ones children answered before choosing a story.

\section{Figure 1}

\section{Choice presentation for Studies 1-3.}




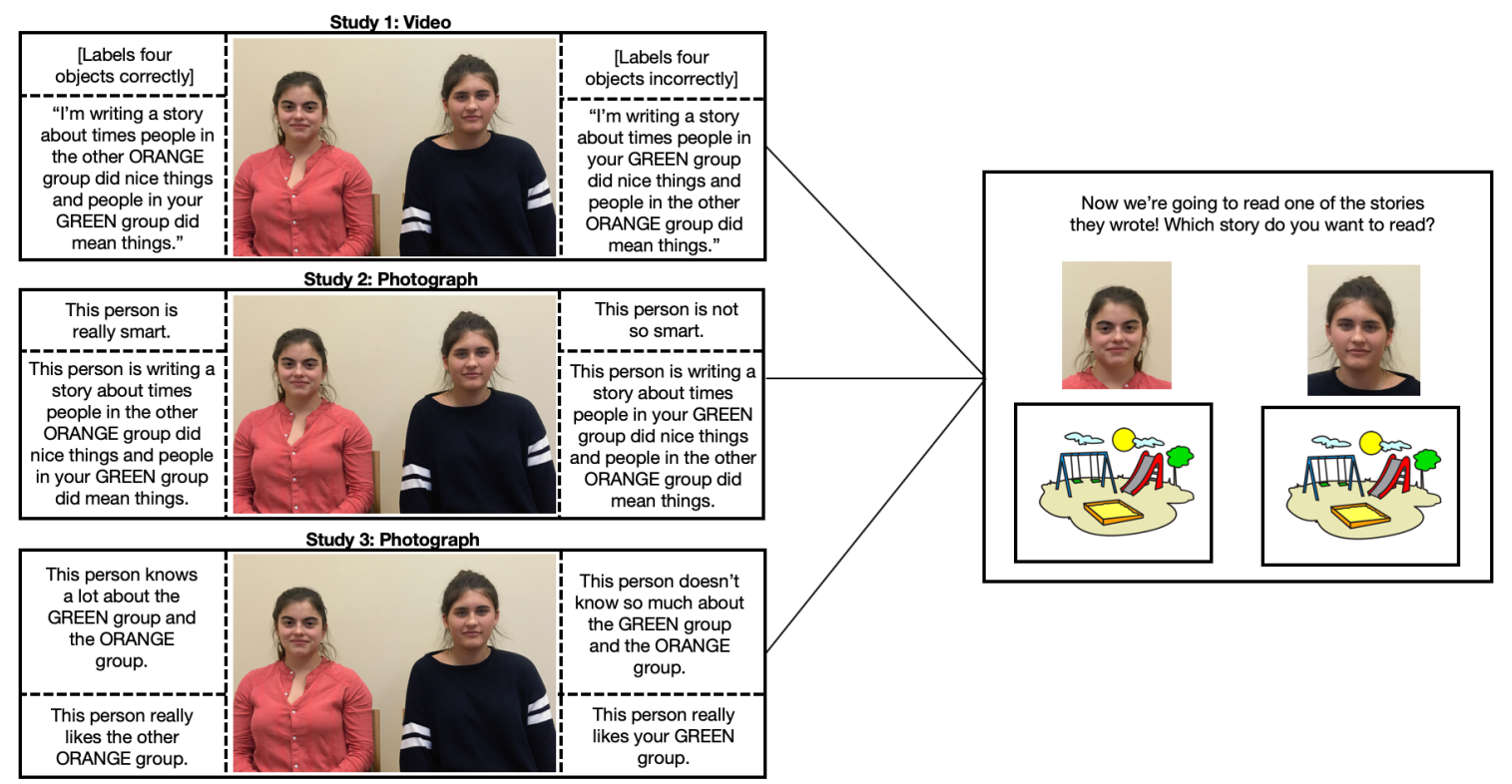

Note. Children evaluated each group, then were given the choice presented here. After children chose a story, the experimenter read the story to them, then asked them to evaluate each group again.

\section{Results}

We first analyzed the proportion of children who chose each story in each condition by subjecting children's choices to a logistic regression model with Condition as a fixed factor. We also tested children's choices against chance, separately by condition, using intercept-only models. Children's story choices varied by condition (see Figure 2). In the reliability condition, children chose the story by the accurate author over the story by the inaccurate author ( 21 out of 24 children, $\chi^{2}(1)=9.94, p=.002$ ), and in the groups condition, children chose the story by the ingroup-favoring author over the story by the outgroup-favoring author (18 out of 24 children, $\left.\chi^{2}(1)=5.43, p=.020\right)$. In the focal condition, children were evenly split between the two stories ( 14 out of 24 children chose the story by the ingroup-favoring but inaccurate author, $\chi^{2}(1)=.660$, $p=.416)$. The difference across the three conditions was marginally significant, $\chi^{2}(2)=4.89, p=$ .087. For exploratory purposes, we also calculated a Bayes Factor to quantify the amount of 
evidence that children in the focal condition did not choose one story more often than the other; the Bayes Factor was 1.71 in favor of the hypothesis that children chose each story $50 \%$ of the time, constituting weak evidence.

\section{Figure 2}

The proportion of children who chose the story of interest in each condition, across studies

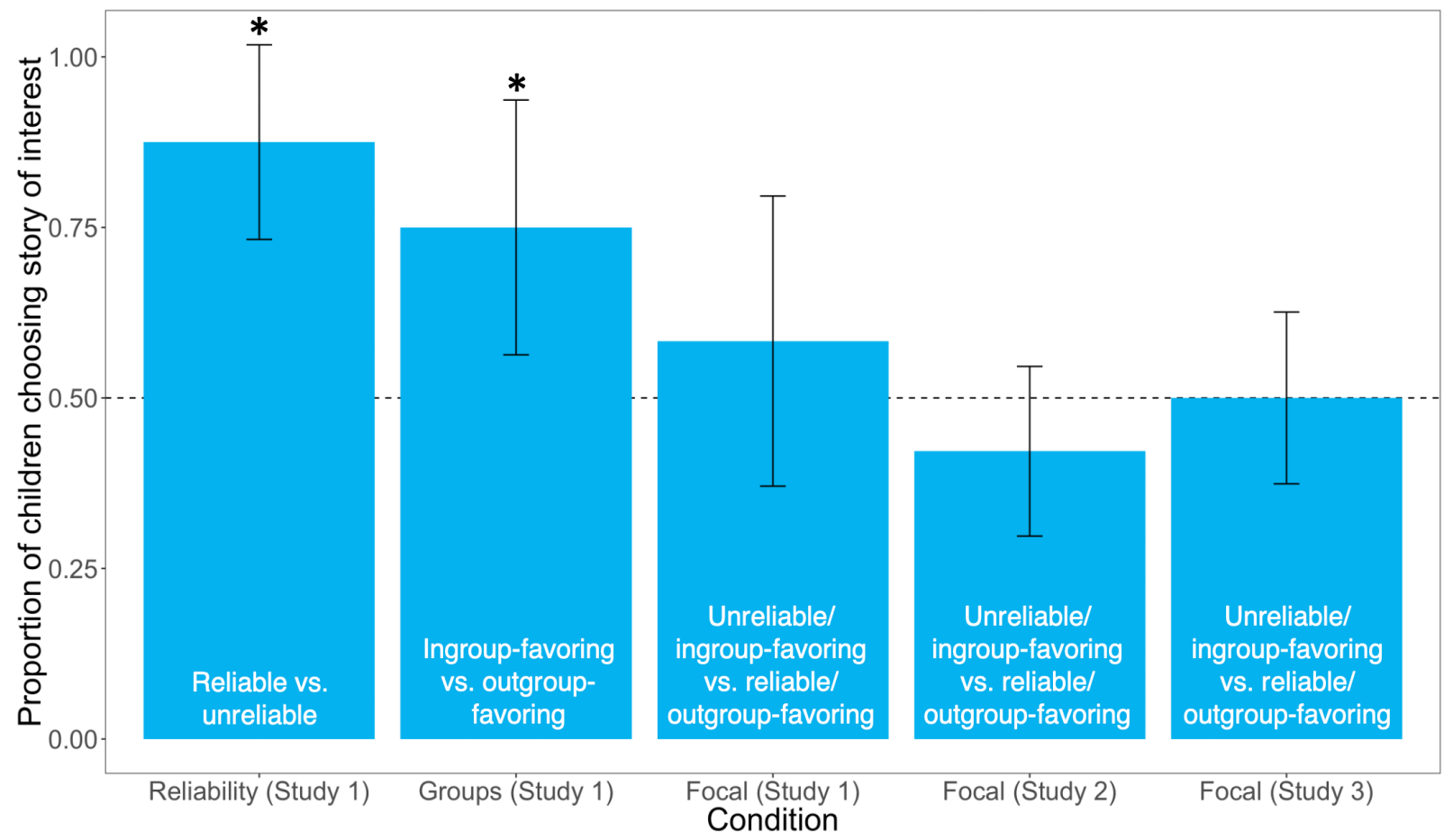

Note. Error bars represent 95\% Confidence Intervals. Asterisks indicate conditions where children's performance differed from that expected by chance. For the focal conditions, the story of interest was the one by the unreliable/ingroup-favoring author.

Next, we analyzed whether and how children's evaluations of the two groups changed in response to the story in the focal condition. We first averaged children's responses to the two liking questions for each group at each time point so that each child had an ingroup evaluation score and an outgroup evaluation score, both before and after hearing the story; each score could range from -2 (strongly dislike) to 2 (strongly like), with 0 indicating neutral attitudes 
(descriptive statistics can be found in Table 1). We then subjected these scores to a repeatedmeasures ANOVA with Group (ingroup or outgroup) and Time (before or after the story) as within-subjects factors, and Story (ingroup-favoring/unreliable or outgroup-favoring/reliable) as a between-subjects factor, testing for all possible main effects and interactions. We followed this analysis with separate repeated-measures ANOVAs for each story.

Generally, children preferred the ingroup to the outgroup (main effect of group, $F(1,66)=$ 34.32, $p<.001)$. However, whether children changed their opinions in response to the story depended marginally on which story they had heard (group by time by story interaction, $F(1,66)$ $=3.09, p=.084)$. Children who heard the story by a reliable but outgroup-favoring author consistently preferred the ingroup before and after hearing the story (main effect of group, $F(1$, $27)=9.53, p=.005)$, whereas children who heard the story by an unreliable but ingroup-favoring author ended up liking the outgroup somewhat less $(p=.069)$ than they originally had (group by time interaction, $F(1,39)=4.71, p=.036)$.

Table 1. Mean evaluations of each group in Study 1 (scores range from -2 [strongly dislike] to 2 [strongly like], with 0 indicating neutral attitudes)

\begin{tabular}{lllll}
\hline Story Chosen & Group & Time & $M$ & $C I$ \\
\hline \multirow{3}{*}{ Reliable/Outgroup-favoring } & \multirow{2}{*}{ Ingroup } & Before & 1.34 & $0.94,1.74$ \\
& & After & 0.97 & $0.46,1.48$ \\
& \multirow{2}{*}{ Outgroup } & Before & 0.08 & $-0.67, .83$ \\
& & After & -0.05 & $-0.94, .73$ \\
& \multirow{2}{*}{ Ingroup } & Before & 1.39 & $1.08,1.69$ \\
& & After & 1.25 & $.086,1.63$ \\
& \multirow{2}{*}{ Outgroup } & Before & 0.29 & $-0.07,0.66$ \\
& & After & 0.04 & $-0.43,0.50$ \\
\hline
\end{tabular}




\section{Discussion}

Replicating prior work (Harris \& Corriveau, 2011; Over et al., 2018), children chose a story by a reliable author over one by an unreliable author, and chose a story by an ingroup-favoring author over one by an outgroup-favoring author. However, when the authors' reliability status and group biases were pitted against one another, children were evenly split between the two. These findings suggest that some children prioritized hearing reliable information, and some prioritized hearing ingroup-favoring information. Furthermore, children who heard the story by an unreliable but ingroup-favoring author became even more biased in response to the story than they originally had been. These findings suggest that children have the potential to be influenced by biased information, even when they know it to be unreliable.

\section{Study 2}

An alternative interpretation of children's Study 1 choices is that children were confused by all of the information they had received, and so chose randomly between the two stories (i.e., that they were not intentionally weighing accuracy against partisanship to make a choice). To rule out this possibility, in Study 2, we replicated the focal condition of Study 1 with a larger group of children and asked children to make additional choices between the two authors outside the story-choice context. In other words, we tested whether children relied upon the authors in contexts that specifically focused on reliability and group concerns. An affirmative answer would suggest that they were indeed tracking all of the relevant information and were able to use that information to guide their decisions.

\section{Methods}

\section{Participants}


Participants were 64 4- to 6-year-old children $(M$ age $=5.74$, range $=4.13-7.02,38$

female, 26 male) recruited at schools and museums in New York City, in the same manner as in Study 1. Participants were 42\% White, 20\% Asian, 3\% Hispanic, 6\% Mixed race, and 28\% Unreported. An additional 39 children were tested but excluded from analysis: 6 because of experimenter error, 2 because of parental interference, 10 because of distractions in the testing environment, and 21 because they failed more than $25 \%$ of the attention check questions.

\section{Procedure}

Scripts and storybooks are available on the the Open Science Framework (https://osf.io/8qv3s/). The procedure for Study 2 was the same as that of the focal condition of Study 1, with the following exceptions. First, the two story authors were displayed in still photographs and described by the experimenter, instead of being portrayed in videos (see Figure 1). To demonstrate that one author was reliable and one wasn't, the experimenter pointed to each of the women in turn and said, "Look at this person. She is [really smart/not so smart]. Today, she saw this animal [experimenter pointed to a picture of a frog] and said, 'That's a [frog/horse]!' Remember, she is [really smart/not so smart].” Describing the authors as smart or not smart was intended to communicate the authors' reliability status in a more explicit way than in Study 1. To describe the authors' group-based biases, the experimenter pointed to each of the women in turn and said, "Look at this person. She is writing a story about times people in your [Green/Orange] group did nice things, and people in the other [Orange/Green] group did mean things."

Second, at the end of the study, children were asked two additional questions in counterbalanced order. One question explored which author children would use to learn information where reliability was important, but group bias was not: Children were shown a 
picture of a novel object (a chestnut roaster) and told, "I bet one of these people can help us figure out what this thing is called. Who do you want to ask what it is called?" The other question explored which author children would choose in a setting where group bias was important, but reliability was not: Children were shown the picture of the two authors again and were asked, "One of these people brought a present for your group. Who do you think brought a present for your group?" The order of these questions was counterbalanced across participants. If children were accurately tracking all of the relevant information, then they should have used the authors' reliability status to guide their choice in the first question, but used the authors' group biases to guide their choice in the second question.

\section{Results}

As in Study 1, we analyzed the proportion of children who chose each story by subjecting children's choices to an intercept-only logistic regression model. We again found that when choosing which story they wanted to hear, children were evenly split between the two authors (27 out of 64 children chose the ingroup-favoring but unreliable story, $\chi^{2}(1)=1.550, p=.213$; see Figure 2). As in Study 1, for exploratory purposes, we also calculated a Bayes Factor to quantify the amount of evidence that children did not choose one story more often than the other; the Bayes Factor was 1.66 in favor of the hypothesis that children chose each story $50 \%$ of the time, constituting weak evidence. Furthermore, we analyzed children's responses to the novel object and present questions using a separate intercept-only logistic regression model for each question. When deciding whom to ask about the name of a novel object, children overwhelmingly chose the reliable author (58 out of 64 children, $\chi^{2}(1)=27.653, p<.001$ ), and when predicting who had brought a present for their ingroup, children chose the ingroup- 
favoring author (42 out of 64 children, $\chi^{2}(1)=6.037, p=.014$ ). Critically, children's answers to these questions were not related to which story they chose ( $p$ s $>.1)$.

We again analyzed whether children's evaluations of the two groups changed in response to the story in the same manner as in Study 1 (descriptive statistics can be found in Table 2). We found that children generally preferred the ingroup to the outgroup (main effect of group, $F(1$, 186) $=27.91, p<.001$ ), but whether children changed their opinions in response to the story depended on which story they had heard (group by time by story interaction, $F(1,186)=4.06, p$ $=.045)$. Children who heard the story by a reliable but outgroup-favoring author did not show a consistent preference for either group before or after hearing the story ( $p$ s $>.164)$. For children who heard the ingroup-favoring but unreliable story, they preferred the ingroup to the outgroup before and after hearing the story (main effect of group, $F(1,78)=59.40, p<.001$ ). For these children, although the interaction between group and time did not reach statistical significance $(p$ $=.137$ ), planned comparisons (part of our preregistered analysis plan) revealed that children's evaluations of the ingroup were similar before and after hearing the story $(p=.476)$, but their evaluations of the outgroup became somewhat more negative $(p=.073)$.

Table 2. Mean evaluations of each group in Study 2 (scores range from -2 [strongly dislike] to 2 [strongly like], with 0 indicating neutral attitudes)

\begin{tabular}{lllll}
\hline Story Chosen & Group & Time & $M$ & $C I$ \\
\hline & \multirow{2}{*}{ Ingroup } & Before & 0.91 & $0.51,1.30$ \\
Reliable/Outgroup-favoring & & After & 0.59 & $0.17,1.02$ \\
& \multirow{2}{*}{ Outgroup } & Before & 0.51 & $0.20,0.83$ \\
& & After & 0.68 & $0.33,1.04$ \\
& \multirow{2}{*}{ Ingroup } & Before & 1.46 & $1.11,1.81$ \\
& & After & 1.56 & $1.26,1.85$ \\
& \multirow{2}{*}{ Outreliable/Ingroup-favoring } & Before & 0.28 & $-0.23,0.78$ \\
& & After & -0.15 & $-0.77,0.47$ \\
\hline
\end{tabular}


Additionally, although it was not a part of our preregistered analysis plan, we decided to explore one potential individual difference among children that may have driven their decisions about which story they wanted to hear. We considered the possibility that children's initial levels of bias may have informed the story choices that they made-specifically, that children who initially felt more of a bias in favor of the ingroup may have been the children who chose to prioritize hearing ingroup-favoring information. By focusing on children's initial evaluations of the two groups, we found that as a whole children initially preferred the ingroup to the outgroup, $F(1,62)=13.62, p<.001$. However, this effect was driven by the children who chose the ingroupfavoring but unreliable story $(F(1,26)=20.16, p<.001)$. In fact, for children who chose the outgroup-favoring but reliable story, the effect of group did not reach significance (although it did trend in the same direction, $F(1,36)=2.47, p=.124$; group by story interaction, $F(1,62)=3.76$, $p=.057)$.

\section{Discussion}

In Study 2, we replicated the results of Study 1, in that neither reliability nor group bias outweighed the other in guiding children's decisions. Roughly half of the children prioritized bias, whereas the other half prioritized reliability. In addition, we uncovered a potential individual difference that may have driven children's choices - the children who chose to prioritize bias were the ones who had been more biased to begin with, suggesting that holding particularly strong biases may have led some children to deprioritize their concern for hearing reliable information. Furthermore, the children who prioritized bias changed their opinion of the 
outgroup in response to the story they heard, even though they knew it came from an unreliable source.

We also found that children used the story authors in systematic ways outside the story choice context, i.e. when making decisions more directly related to reliability and group membership. This strongly suggests that their choices were not random or the result of confusion, but were intentional choices about whom children would rather learn from. Furthermore, this finding suggests that the relative importance of reliability and group membership for children varies depending on the specific circumstances they are in, such that they flexibly shift their concern toward the factor that is more directly relevant to the particular problem they are trying to solve.

\section{Study 3}

The goal of Study 3 was to conceptually replicate Studies 1 and 2 with a manipulation that more closely mirrored the way potential informants are likely introduced to children in the real world. Children probably aren't often told explicitly that the people around them are or aren't smart, but they do often receive input to suggest that people have expertise in certain areas of knowledge. Thus, we now introduced the authors as either "knowing a lot" or "not knowing so much" about the two groups. We also wanted to make the authors' partisan biases even more clear than they had been in Studies 1 and 2, so we described the authors as being even more explicitly biased in favor of one group or the other.

\section{Methods}

\section{Participants}

Participants were $644-$ to 6-year-old children $(M$ age $=5.70$, range $=4.04-6.93,34$ female, 30 male) recruited at schools, public parks, and museums in the New York City area, in 
the same manner as in Studies 1 and 2. Participants were 20\% White, 3\% Black, 11\% Asian, 6\% Hispanic, 5\% Mixed race, and 55\% Unreported. An additional 17 children were tested but excluded from analysis: 2 because of experimenter error, 4 because of parental interference, 4 because of distractions in the testing environment, 4 for failing to complete the entire activity, and 3 because they failed more than $25 \%$ of the attention check questions.

\section{Procedure}

Scripts and storybooks are available on the Open Science Framework (https://osf.io/8qv3s/). The procedure for Study 3 was the same as that of Study 2, with two exceptions. First, the authors' group bias and reliability status were introduced as follows. To demonstrate that one story author was reliable and one wasn't, the experimenter pointed to each of the women in turn and said, "Look at this person. She [knows a lot/doesn't know so much] about the green group and the orange group. When people ask her questions about the groups, she [usually gets them right/sometimes gets them right and sometimes gets them wrong." To describe the authors' group-based biases, the experimenter pointed to each of the women in turn and said, "This person really likes [your/the other] [green/orange] group." Second, children were not asked additional questions about which author they would turn to outside the story-choice context.

\section{Results}

We analyzed children's responses in the same manner as in Studies 1 and 2. Once again, when choosing a story, children were evenly split between the two authors (32 out of 64 children chose the ingroup-favoring but unreliable story, $\chi^{2}(1)=0.00, p>.999$; see Figure 2$)$. As in Studies 1 and 2, for exploratory purposes, we also calculated a Bayes Factor to quantify the amount of evidence that children did not choose one story more often than the other; the Bayes 
Factor was 3.37 in favor of the hypothesis that children chose each story $50 \%$ of the time, constituting moderate evidence in favor of that hypothesis. Furthermore, again, children generally preferred the ingroup to the outgroup (main effect of group, $F(1,186)=6.55, p=$ .011), but whether children changed their opinions in response to the story depended on which story they had heard (group by time by story interaction, $F(1,186)=9.64, p=.002$; descriptive statistics can be found in Table 3). For children who heard the story by a reliable but outgroupfavoring author, their opinions of the ingroup became less positive after hearing the story $(p<$ $.001)$, whereas their evaluations of the outgroup did not change ( $p=.315$; group by time interaction, $F(1,93)=5.24, p=.024)$. For children who heard the ingroup-favoring but unreliable story, this pattern was reversed: Their opinions of the ingroup did not change after hearing the story $(p=.236)$, but their evaluations of the outgroup became more negative $(p=$ .011 ; group by time interaction, $F(1,93)=4.40, p=.039)$. In addition, children who chose the ingroup-favoring but unreliable story were initially heavily biased in favor of their ingroup $(F(1$, $31)=13.09, p=.001)$, whereas children who chose the outgroup-favoring but reliable story initially did not show a preference between the two groups $(p=.379$; group by story interaction, $F(1,62)=10.37, p=.002)$.

Table 3. Mean evaluations of each group in Study 3 (scores range from -2 [strongly dislike] to 2 [strongly like], with 0 indicating neutral attitudes)

\begin{tabular}{lllll}
\hline Story Chosen & Group & Time & $M$ & $C I$ \\
\hline \multirow{3}{*}{ Reliable/Outgroup-favoring } & \multirow{2}{*}{ Ingroup } & Before & 0.83 & $0.38,1.28$ \\
& & After & 0.13 & $-0.43,0.68$ \\
& \multirow{2}{*}{ Outgroup } & Before & 1.08 & $0.72,1.43$ \\
& & After & 1.23 & $0.79,1.68$ \\
Unreliable/Ingroup-favoring & Ingroup & Before & 1.39 & $1.01,1.78$ \\
& & After & 1.60 & $1.31,1.91$ \\
& Outgroup & Before & 0.34 & $-0.11,0.80$ \\
\hline
\end{tabular}


After $\quad-0.27 \quad-0.80,-0.27$

\section{Discussion}

In Study 3, we again replicated the finding that children care both about informant reliability and group biases when seeking information, and that children's choices are guided by individual differences in their initial levels of bias. We also again found that children changed their opinion of the outgroup in response to the story, even though they knew that it came from an unreliable source.

\section{Combined Analyses}

The above analyses reflect a number of findings that were replicated across our three studies, as well as some that differed from study to study. Some of the discrepancies across studies may have arisen because our sample sizes, although based on prior work, were relatively small. To increase statistical power and test which of our findings were idiosyncratic and which were consistent across studies, we pooled our data across the three studies (focusing only on the focal condition in Study 1) and re-ran our main analyses, including study as a between-subjects factor. This resulted in a total sample of 152 children. Across studies, children were similarly split between the two stories ( 79 vs. $73 ; \chi^{2}(1)=.08, p=.783$, no effect of study, $\mathrm{BF}=4.50$ in favor of the hypothesis that children chose each story $50 \%$ of the time, constituting moderate evidence).

Furthermore, as shown in Figure 3, across the three studies, whether children changed their opinion in response to the story depended on which story they heard (group by time by story interaction, $F(1,444)=15.68, p<.001$, no interaction with study, see Table 4 for descriptive statistics). For children who heard the ingroup-favoring but unreliable story, their evaluations of the outgroup became more negative after hearing the story $(p<.001)$, and their 
opinions of the ingroup became somewhat more positive $(p=.055$; group by time interaction, $F(1,216)=10.65, p=.001)$. For children who heard the story by a reliable but outgroupfavoring author, their opinions of the ingroup became more negative after hearing the story ( $p<$ $.001)$, whereas their evaluations of the outgroup did not change ( $p=.310$; group by time interaction, $F(1,234)=5.33, p=.021)$. Thus, most of the time, children changed their opinions in line with the information they had heard, regardless of whether or not it came from a reliable source.

In addition, we found that children's story choices may have been driven by individual differences in their initial levels of bias: Children who chose the ingroup-favoring but unreliable story were initially heavily biased in favor of their ingroup $(F(1,72)=36.01, p<.001)$, whereas children who chose the outgroup-favoring but reliable story initially did not show a preference between the two groups ( $p=.137$; group by story interaction, $F(1,148)=9.58, p=.002)$. This was the only effect across our combined analyses that interacted with study $(F(1,148)=5.54, p$ $=.020)$ : The group by story interaction was only significant in Studies 2 and 3.

We also performed a final exploratory analysis looking at whether the degree to which children's biases changed depending on which story they heard. To calculate the degree of change, we first calculated a polarization score for each child, before and after the story, by subtracting their evaluations of the outgroup from their evaluations of the ingroup at each time point. We then calculated the difference between these polarization scores across the two time points, resulting in a "degree of change" score for each child. An independent samples $t$-test on these scores revealed that the degree of change did not differ across the two stories $(t(150)=$ $.258, p=.797$ ), suggesting that children's opinions of the two groups changed after hearing the outgroup-favoring, reliable story to the same degree to which children's opinions of the two 
groups changed after hearing the ingroup-favoring, unreliable story. Thus, the degree of change in children's opinions was equally strong, regardless of whether children heard the reliable or unreliable story.

\section{Figure 3}

Children's evaluations of the two groups, before and after hearing the story, depending on which story they heard

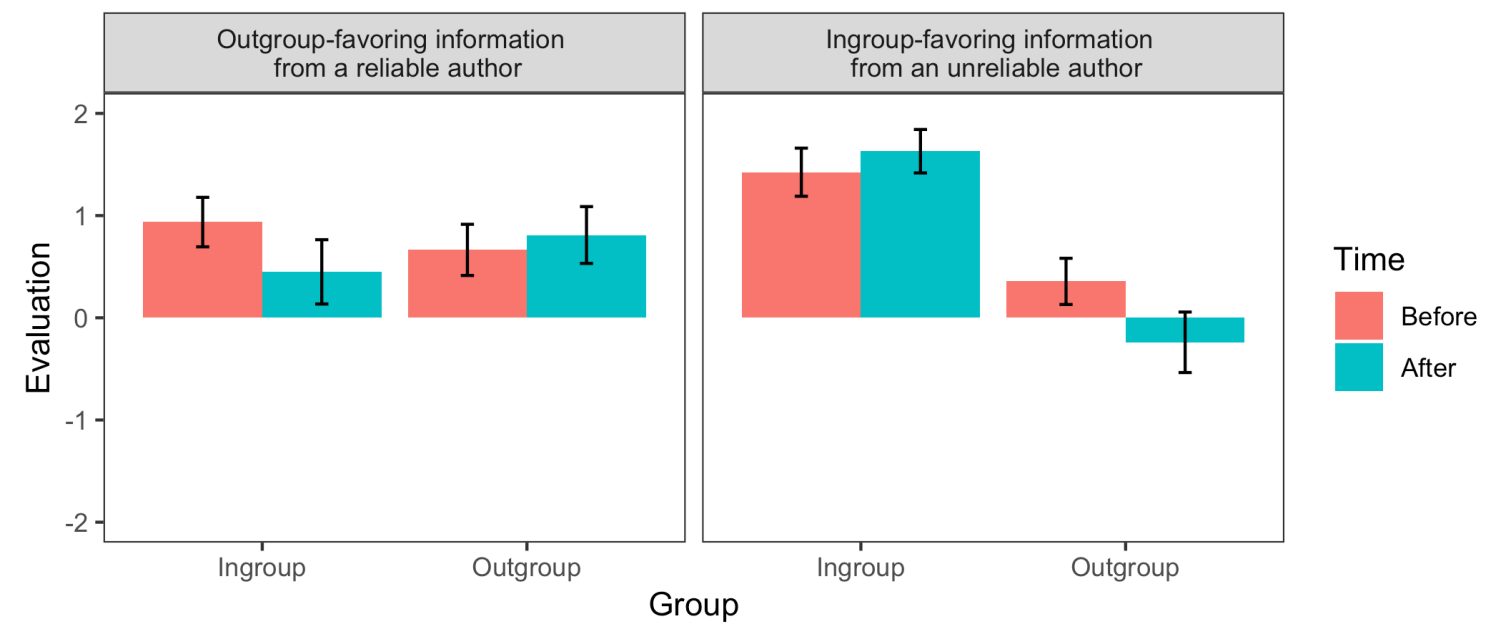

Note. Children heard the story that they had chosen in the first part of the study. Error bars represent $95 \%$ Confidence Intervals. See OSF page for data plotted separately by study.

Table 4. Mean evaluations of each group, collapsed across the three studies (scores range from 2 [strongly dislike] to 2 [strongly like], with 0 indicating neutral attitudes)

\begin{tabular}{lllll}
\hline Story Chosen & Group & Time & $M$ & $C I$ \\
\hline \multirow{3}{*}{ Reliable/Outgroup-favoring } & \multirow{2}{*}{ Ingroup } & Before & 0.93 & $0.67,1.20$ \\
& & After & 0.45 & $0.14,0.76$ \\
& \multirow{2}{*}{ Outgroup } & Before & 0.66 & $0.42,0.91$ \\
& \multirow{2}{*}{ Ingroup } & After & 0.81 & $0.52,1.10$ \\
Unreliable/Ingroup-favoring & & Before & 1.42 & $1.20,1.65$ \\
& \multirow{2}{*}{ Outgroup } & Befter & 1.63 & $1.46,1.80$ \\
& & After & -0.24 & $-0.06,0.65$ \\
& & & & \\
\hline
\end{tabular}

\section{General Discussion}


The present studies tested how children weigh accuracy against partisanship as they seek information about the world. When given a choice between hearing information that was reliable, but biased in favor of the outgroup, versus information that was unreliable, but biased in favor of the ingroup, children were consistently split between the two. Further inspection of Bayes Factors associated with this finding provided moderate evidence in favor of the hypothesis that children were split between these two factors. Nonetheless, caution is warranted in interpreting null findings such as these. Yet, given that children did use both authors systematically outside the story-choice context (and thus were tracking all of the relevant information and intentionally making their decisions on the basis of it), we interpret this finding as evidence for a tension in children's thinking: Children want to pursue both accurate and biasconfirming information, such that when they are forced to choose between the two, some children prioritize accuracy, and some prioritize bias.

This finding dovetails with prior developmental research, which has shown that group biases and informant reliability are both influential concerns for young children (Baron \& Banaji, 2006; Dunham et al., 2011; Elashi \& Mills, 2014; Harris et al., 2018; Harris \& Corriveau, 2011; Koenig et al., 2004; Over et al., 2018; Pasquini et al., 2007; Zhang \& Sylva, 2021). Yet, unlike most prior work on information seeking, which has focused on children's search for information about how to label and use novel objects, we have shown that children's concern for both partisanship and accuracy extends to situations where children are seeking information about social groups themselves. We have also extended prior work by documenting how children adjust their prior knowledge in response to the information they have sought out, showing that children do change their beliefs in response to this information, regardless of how reliable it is. 
What accounts for children's decision to prioritize either accuracy or partisanship when seeking information? There are a number of possible individual difference factors that may drive children to prioritize one of these concerns over the other. We found that children's initial levels of polarization may be one of those factors - children who were initially more biased in favor of the ingroup were more likely to choose the ingroup-favoring, but unreliable, story. This finding suggests that children who hold strong biases in favor of ingroup members, or against outgroup members, are likely to become more polarized over time, as they seek out information that affirms those beliefs (even at the expense of accuracy). Future research might test this and other possibilities more directly by experimentally manipulating some of the motivational factors that could drive children to prioritize either accuracy or partisanship. For example, future work might test whether emphasizing the importance of critical thinking would lead children to prioritize accuracy more than they did in the studies reported here, an approach that has been fruitful in adult work (Pennycook et al., 2021). Future work could also address this issue further by checking for consistency in situations where children are tasked with making multiple information-seeking decisions over time.

The present findings - that some, but not all children prioritize partisanship over accuracy when seeking information — make sense in light of research with adults regarding the sharing of misinformation online (Allcott \& Gentzkow, 2017; Lazer et al., 2018; Pennycook et al., 2021). Recent findings suggest that many people are susceptible to misinformation even though they have the cognitive tools to recognize it as inaccurate (Pennycook et al., 2020; Pennycook \& Rand, 2019b). Some work has even shown that people intentionally spread misinformation with the purpose of derogating outgroup members (Osmundsen et al., 2021). Misinformation therefore represents one area where people overlook their concerns for accuracy in order to pursue 
information that satisfies their partisan motivational goals (Brady et al., 2020; Van Bavel \& Pereira, 2018). The present findings suggest that these tendencies may have their origins in early childhood (see also Roberts et al., 2021, for a discussion of whether children believe that people should agree with ingroup members' inaccurate beliefs). We note, however, that we tested a relatively narrow age range in these studies, and that future work could test a wider range of both children and adults to fully flesh out how information-seeking tendencies in intergroup contexts change or remain continuous across development. Furthermore, the present work cannot distinguish whether the children who prioritized partisanship did so because of motivations to enhance the ingroup or derogate the outgroup (or both). Prior work suggests that ingroup positivity generally outweighs outgroup negativity in guiding children's information-seeking tendencies (Over et al., 2018), but future work could more directly test this question.

Interestingly, one commonality between the present studies and work with adults is that misinformation does not appeal equally to everyone; there is individual variation in how much people share and believe in misinformation, just like we found in the current studies for children's prioritization of partisanship. Furthermore, a factor that seems to have driven children's choices — initial levels of polarization — may account for some of the variation that exists among adults. People who are deeply invested in a given topic are more likely to cling to polarized views (Kahan et al., 2012, 2017), and people who are more interested in comparing themselves to others are more likely to pursue news articles that confirm their prior beliefs (Knobloch-Westerwick et al., 2017). It stands to reason, then, that the people who care most about ingroup-outgroup comparisons - those who are most polarized - may be the ones who are particularly susceptible to misinformation (although we acknowledge that our data do not speak directly to this question). 
As noted above, not only did some children seek out content akin to misinformation, but they also changed their opinions in response to it. Children who heard a story that presented positive information about the ingroup and negative information about the outgroup, but had been written by an unreliable author, became more polarized after hearing that story. Thus, children updated their beliefs based on the information they heard, even though they knew that it came from an unreliable source. In fact, children learned from unreliable information to the same degree that they learned from reliable information (although we did not experimentally manipulate which story children heard, independent of which type of information they wanted to pursue - future work should address this issue). This finding points to one of the reasons misinformation, especially in the political world, can be dangerous: It increases animosity among an already-polarized electorate (Stroud, 2010; Vicario et al., 2016). The present findings demonstrate that this pernicious effect may have its roots in some of the earliest-emerging components of the human mind, and so might drive ideological polarization from much earlier than previously acknowledged.

The children who heard the reliable, outgroup-favoring story changed their beliefs after hearing the story as well. For these children, after hearing outgroup-favoring information, their opinions of the ingroup became more negative, whereas their opinions of the outgroup did not change. This finding suggests that these children did update their beliefs in line with the information that they had heard in the story. Interestingly, though, they did not update their beliefs about the ingroup and the outgroup similarly, even though the story did contain both positive information about the ingroup and negative information about the outgroup. This may mean that children not only differ in the extent to which they seek out ingroup-favoring information, but that they also differ in the extent to which they internalize information about the 
ingroup versus information about the outgroup. Children may consider information about the ingroup to be particularly important, and therefore might weigh this information more heavily than information about the outgroup when updating their attitudes. This finding also may reflect children's motives in choosing the outgroup-favoring story; perhaps these children were particularly open to critiques of their ingroup (consistent with the fact that they did not hold a strong ingroup bias to begin with), and therefore focused more on ingroup-derogating information when listening to the story that they had chosen. Another possibility is that these children internalized the negative information that they heard more than the positive information, consistent with work documenting a negativity bias in children's processing of social information (Doebel \& Koenig, 2013; Kinzler \& Shutts, 2008; LoBue, 2009). Future work should directly test why children might update their group-related beliefs in asymmetric ways.

This work is not without limitations. In Studies 1 and 2, a substantial number of children needed to be excluded because they failed to correctly answer attention check questions. We established our exclusion criteria prior to data collection, and these criteria resulted in a higher number of children being excluded than we expected. This is likely because the wording of the attention check questions may have been confusing to some children. The fact that we found the same patterns when we re-ran the analyses including all of the excluded children suggests that these exclusions do not reflect systematic differences in how children responded to our main measures - rather, they likely reflect a problem with the attention check questions themselves. Still, future research might explore the individual differences that may have made children more or less likely to answer these questions correctly.

Another limitation of the present work is that it only allows us to draw concrete conclusions regarding children's beliefs about minimal groups. Using minimal groups in these 
studies allowed us to test children's beliefs about groups in general, regardless of any specific knowledge they might have (or pre-existing biases they might hold) about the groups in their everyday environment. Thus, our findings using this paradigm show that children often seek out ingroup-favoring information, even when the ingroup in question is relatively meaningless. An important direction for future work will be to explore how these findings extend to the groups that children are a part of in their everyday lives (e.g., gender, race). Such work would allow us to test how children's information-seeking tendencies vary depending on the strength of their affiliations with different groups.

One final limitation of our approach in the present work regards an ambiguity around children's exact goals in making a choice between the two stories they were presented with. We believe that children made their choices based on which type of information-accuracy or partisanship — they were motivated to pursue. An alternate possibility, however, is that instead of seeking information that would satisfy accuracy-related or partisan goals, children interpreted the task as providing conflicting information about which author is an ingroup member, whom they should turn to for information about what to think. On this account, some children may actually be using accuracy as another cue to ingroup status. We favor the interpretation that children's choices reflect their information-seeking goals, in light of the wealth of prior research documenting that children pursue both accurate information (Clément et al., 2004; Harris et al., 2018; Harris \& Corriveau, 2011; Koenig et al., 2004; Koenig \& Harris, 2005; Pasquini et al., 2007) and information that confirms their partisan biases (Elashi \& Mills, 2014; Hetherington et al., 2014; MacDonald et al., 2013; Zhang \& Sylva, 2021) in paradigms very similar to the one we used here (Over et al., 2018). Yet, our data cannot fully rule out this alternative. Regardless, either interpretation speaks to the same broader conclusion - that accuracy and partisanship are 
both important concerns for young children, and which they prioritize (in seeking information, or in assessing who is an ingroup member) informs whether and how the information they hear will influence their preexisting biases. Still, the exact goal driving children's choices in the present work remains an open question.

In addition to those already mentioned, this research opens up various directions for future research. First, it will be valuable to further investigate the characteristics that lead children to prioritize either accuracy or partisanship. As noted above, we did document one such characteristic: Children's initial levels of polarization informed whether they prioritized hearing ingroup-favoring information. In addition, though, several individual features have been shown to predict adults' susceptibility to misinformation, in particular analytical thinking and cognitive reflection (Pennycook \& Rand, 2019a, 2019b); similar predictive factors could drive children's information seeking tendencies. Relatedly, it will be useful for future research to explore whether the tendency to seek either partisan or accurate information is stable in individuals over time, perhaps by asking participants to make multiple information-seeking decisions in a variety of circumstances. It will also be important for future research to explore how children's information-seeking tendencies shift depending on the task at hand. For example, children might prioritize accuracy more while taking a high-stakes test, versus while taking part in an intergroup competition. Finally, future research should explore ways of encouraging children and adults to focus more on accuracy while consuming information. The present findings may be alarming in that they suggest that susceptibility to misinformation is a fundamental component of human cognition. Yet, this account also gives reason to be hopeful. By targeting the right learning mechanisms early in life, we may be able to prevent the spread of misinformation before it starts. 


\section{References}

Allcott, H., \& Gentzkow, M. (2017). Social media and fake news in the 2016 election. Journal of Economic Perspectives, 31(2), 211-236. https://doi.org/10.1257/jep.31.2.211

Baron, A. S., \& Banaji, M. R. (2006). The development of implicit attitudes: Evidence of race evaluations from ages 6 and 10 and adulthood. Psychological Science, 17(1), 53-58. https://doi.org/10.1111/j.1467-9280.2005.01664.x

Brady, W. J., Crockett, M. J., \& Van Bavel, J. J. (2020). The MAD Model of Moral Contagion: The Role of Motivation, Attention, and Design in the Spread of Moralized Content Online. Perspectives on Psychological Science, 15(4), 978-1010. https://doi.org/10.1177/1745691620917336

Chouinard, M. M., Harris, P. L., \& Maratsos, M. P. (2007). Children's Questions: A Mechanism for Cognitive Development. Monographs of the Society for Research in Child Development, 72(1), i-129. JSTOR.

Clément, F., Koenig, M., \& Harris, P. (2004). The Ontogenesis of Trust. Mind \& Language, 19(4), 360-379. https://doi.org/10.1111/j.0268-1064.2004.00263.x

Corriveau, K. H., Kinzler, K. D., \& Harris, P. L. (2013). Accuracy trumps accent in children’s endorsement of object labels. Developmental Psychology, 49(3), 470-479. https://doi.org/10.1037/a0030604

Corriveau, K., \& Harris, P. L. (2009). Choosing your informant: Weighing familiarity and recent accuracy. Developmental Science, 12(3), 426-437. https://doi.org/10.1111/j.14677687.2008.00792.x 
Doebel, S., \& Koenig, M. A. (2013). Children's use of moral behavior in selective trust:

Discrimination versus learning. Developmental Psychology, 49(3), 462-469. https://doi.org/10.1037/a0031595

Dunham, Y., Baron, A. S., \& Banaji, M. R. (2006). From American city to Japanese village: A cross-cultural investigation of implicit race attitudes. Child Development, 77(5), 12681281. https://doi.org/10.1111/j.1467-8624.2006.00933.x

Dunham, Y., Baron, A. S., \& Carey, S. (2011). Consequences of "minimal” group affiliations in children. Child Development, 82(3), 793-811. https://doi.org/10.1111/j.14678624.2011.01577.x

Dunham, Y., \& Emory, J. (2014). Of affect and ambiguity: The emergence of preference for arbitrary ingroups. Journal of Social Issues, 70(1), 81-98. https://doi.org/10.1111/josi.12048

Elashi, F. B., \& Mills, C. M. (2014). Do children trust based on group membership or prior accuracy? The role of novel group membership in children's trust decisions. Journal of Experimental Child Psychology, 128, 88-104. https://doi.org/10.1016/j.jecp.2014.07.003

Gopnik, A., \& Meltzoff, A. N. (1997). Words, thoughts, and theories. MIT Press.

Gopnik, A., \& Wellman, H. M. (2012). Reconstructing constructivism: Causal models, Bayesian learning mechanisms, and the theory theory. Psychological Bulletin, 138(6), 1085-1108. https://doi.org/10.1037/a0028044

Halim, M. L. D., Ruble, D. N., Tamis-LeMonda, C. S., Shrout, P. E., \& Amodio, D. M. (2017). Gender attitudes in early childhood: Behavioral consequences and cognitive antecedents. Child Development, 88(3), 882-899. https://doi.org/10.1111/cdev.12642 
Harris, P. L., \& Corriveau, K. H. (2011). Young children's selective trust in informants.

Philosophical Transactions of the Royal Society B: Biological Sciences, 366(1567), 1179-1187. https://doi.org/10.1098/rstb.2010.0321

Harris, P. L., Koenig, M. A., Corriveau, K. H., \& Jaswal, V. K. (2018). Cognitive foundations of learning from testimony. Annual Review of Psychology, 69(1), 251-273. https://doi.org/10.1146/annurev-psych-122216-011710

Heiphetz, L., Spelke, E. S., \& Banaji, M. R. (2013). Patterns of implicit and explicit attitudes in children and adults: Tests in the domain of religion. Journal of Experimental Psychology: General, 142(3), 864-879. https://doi.org/10.1037/a0029714

Hetherington, C., Hendrickson, C., \& Koenig, M. (2014). Reducing an in-group bias in preschool children: The impact of moral behavior. Developmental Science, 17(6), 1042-1049. https://doi.org/10.1111/desc.12192

Jaswal, V. K., \& Neely, L. A. (2006). Adults don't always know best: Preschoolers use past reliability over age when learning new words. Psychological Science, 17(9), 757-758. https://doi.org/10.1111/j.1467-9280.2006.01778.x

Kahan, D. M., Peters, E., Dawson, E. C., \& Slovic, P. (2017). Motivated numeracy and enlightened self-government. Behavioural Public Policy, 1(1), 54-86. https://doi.org/10.1017/bpp.2016.2

Kahan, D. M., Peters, E., Wittlin, M., Slovic, P., Ouellette, L. L., Braman, D., \& Mandel, G. (2012). The polarizing impact of science literacy and numeracy on perceived climate change risks. Nature Climate Change, 2(10), 732-735. https://doi.org/10.1038/nclimate1547 
Kinzler, K. D., Dupoux, E., \& Spelke, E. S. (2007). The native language of social cognition. Proceedings of the National Academy of Sciences, 104(30), 12577-12580. https://doi.org/10.1073/pnas.0705345104

Kinzler, K. D., \& Shutts, K. (2008). Memory for "mean" over "nice": The influence of threat on children's face memory. Cognition, 107(2), 775-783. https://doi.org/10.1016/j.cognition.2007.09.005

Knobloch-Westerwick, S., Mothes, C., \& Polavin, N. (2017). Confirmation Bias, Ingroup Bias, and Negativity Bias in Selective Exposure to Political Information: Communication Research. https://doi.org/10.1177/0093650217719596

Koenig, M. A., Clément, F., \& Harris, P. L. (2004). Trust in testimony: Children's use of true and false statements. Psychological Science, 15(10), 694-698. https://doi.org/10.1111/j.0956-7976.2004.00742.x

Koenig, M. A., \& Harris, P. L. (2005). Preschoolers Mistrust Ignorant and Inaccurate Speakers. Child Development, 76(6), 1261-1277. https://doi.org/10.1111/j.1467-8624.2005.00849.x

Lazer, D. M. J., Baum, M. A., Benkler, Y., Berinsky, A. J., Greenhill, K. M., Menczer, F., Metzger, M. J., Nyhan, B., Pennycook, G., Rothschild, D., Schudson, M., Sloman, S. A., Sunstein, C. R., Thorson, E. A., Watts, D. J., \& Zittrain, J. L. (2018). The science of fake news. Science, 359(6380), 1094-1096. https://doi.org/10.1126/science.aao2998

LoBue, V. (2009). More than just another face in the crowd: Superior detection of threatening facial expressions in children and adults. Developmental Science, 12(2), 305-313. https://doi.org/10.1111/j.1467-7687.2008.00767.x 
MacDonald, K., Schug, M., Chase, E., \& Barth, H. (2013). My people, right or wrong? Minimal group membership disrupts preschoolers' selective trust. Cognitive Development, 28(3), 247-259. https://doi.org/10.1016/j.cogdev.2012.11.001

Nickerson, R. S. (1998). Confirmation Bias: A Ubiquitous Phenomenon in Many Guises. Review of General Psychology, 2(2), 175-220.

Osmundsen, M., Bor, A., Vahlstrup, P. B., Bechmann, A., \& Petersen, M. B. (2021). Partisan Polarization Is the Primary Psychological Motivation behind Political Fake News Sharing on Twitter. American Political Science Review, 115(3), 999-1015.

https://doi.org/10.1017/S0003055421000290

Over, H., Eggleston, A., Bell, J., \& Dunham, Y. (2018). Young children seek out biased information about social groups. Developmental Science, 21(3), e12580. https://doi.org/10.1111/desc. 12580

Pasquini, E. S., Corriveau, K. H., Koenig, M., \& Harris, P. L. (2007). Preschoolers monitor the relative accuracy of informants. Developmental Psychology, 43(5), 1216-1226. https://doi.org/10.1037/0012-1649.43.5.1216

Pennycook, G., Epstein, Z., Mosleh, M., Arechar, A. A., Eckles, D., \& Rand, D. G. (2021). Shifting attention to accuracy can reduce misinformation online. Nature, 592(7855), 590595. https://doi.org/10.1038/s41586-021-03344-2

Pennycook, G., McPhetres, J., Zhang, Y., Lu, J. G., \& Rand, D. G. (2020). Fighting COVID-19 misinformation on social media: Experimental evidence for a scalable accuracy-nudge intervention. Psychological Science, 31(7), 770-780.

https://doi.org/10.1177/0956797620939054 
Pennycook, G., \& Rand, D. G. (2019a). Who Falls for Fake News? The Roles of Bullshit Receptivity, Overclaiming, Familiarity, and Analytic Thinking (SSRN Scholarly Paper ID 3023545). Social Science Research Network. https://papers.ssrn.com/abstract=3023545

Pennycook, G., \& Rand, D. G. (2019b). Lazy, not biased: Susceptibility to partisan fake news is better explained by lack of reasoning than by motivated reasoning. Cognition, 188, 3950. https://doi.org/10.1016/j.cognition.2018.06.011

Roberts, S. O., Ho, A. K., \& Gelman, S. A. (2021). Should Individuals Think Like Their Group? A Descriptive-to-Prescriptive Tendency Toward Group-Based Beliefs. Child Development, 92(2). https://doi.org/10.1111/cdev.13448

Schmidt, M. F. H., Rakoczy, H., \& Tomasello, M. (2012). Young children enforce social norms selectively depending on the violator's group affiliation. Cognition, 124(3), 325-333. https://doi.org/10.1016/j.cognition.2012.06.004

Stroud, N. J. (2010). Polarization and partisan selective exposure. Journal of Communication, 60(3), 556-576. https://doi.org/10.1111/j.1460-2466.2010.01497.x

Van Bavel, J. J., \& Pereira, A. (2018). The partisan brain: An identity-based model of political belief. Trends in Cognitive Sciences, 22(3), 213-224. https://doi.org/10.1016/j.tics.2018.01.004

Vicario, M. D., Bessi, A., Zollo, F., Petroni, F., Scala, A., Caldarelli, G., Stanley, H. E., \& Quattrociocchi, W. (2016). The spreading of misinformation online. Proceedings of the National Academy of Sciences, 113(3), 554-559. https://doi.org/10.1073/pnas.1517441113 
Wellman, H., \& Gelman, S. A. (1992). Cognitive development: Foundational theories of core domains. Annual Review of Psychology, 43(1), 337-375.

https://doi.org/10.1146/annurev.psych.43.1.337

Zhang, M., \& Sylva, K. (2021). Effects of group membership and visual access on children's selective trust in competitive and non-competitive contexts. Cognitive Development, 57, 100972. https://doi.org/10.1016/j.cogdev.2020.100972 